Www.jmscr.igmpublication.org Impact Factor 5.84

Index Copernicus Value: 83.27

ISSN (e)-2347-176x ISSN (p) 2455-0450

crossref DOI: https://dx.doi.org/10.18535/jmscr/v5i2.25

Journal Of Medical Science And Clinical Research

IGM Publication

An Official Publication of IGM Publication

\title{
Morbidity Mortality Cost, In Survival Estimates of Gastrointestinal Anastamotic Leaks
}

\author{
Authors
Dr A.Y.Kshirsagar, Dr Tanmay Mehta, Dr Nitinchandra Khairnair, Dr Rajath Rakshit R

\begin{abstract}
Objective: to evaluate the clinical and economic burden associated with anastomotic leaks following intestinal anastamosis.

Methods: Retrospective data (January 2014 to December 2016) were analyzed from patients who had undergone gastrointestinal anastamosis with and without postoperative leaks, using the Premier Perspective ${ }^{\mathrm{TM}}$ database. Data on in-hospital mortality, length of stay (LOS), re-admissions, postoperative infection, and costs were analyzed using univariate and multivariate analyses, and the propensity score matching (PSM) and generalized linear models (GLM).

Results: Of the patients 6,174 (6.18\%) had anastomotic leaks within 30 days after gastrointestinal anastamosis surgery. Patients with leaks had 1.3 times higher 30-day re-admission rate Anastomotic leaks are one of the most serious complications that occur after gastrointestinal surgery. They add to potential postoperative patient morbidities and to overall costs of post-operative patient care, including associated hospital readmissions. Further, reoperations and complications such as leaks are considered a quality indicator in colorectal surgery. ${ }^{l}$

Patients developing anastomotic leaks after undergoing gastrointestinal anastamosis exhibit poorer long-term functional results; in the case of malignancy, increased local recurrence rates and reduced 5-year survival are seen.2-4 The clinical manifestations of anastomotic leaks will often warrant hospital re-admission, placing a considerable additional burden on patients and healthcare providers. Overall, anastomotic leaks after colorectal surgery have devastating implications, with significantly greater chances of wound infection and mortality rates of up to 32\%.5, 6 In addition to potential negative clinical outcomes, there is a significant economic and healthcare utilization burden to be considered. While postoperative complications have a dramatic impact on full in-hospital costs per case and are the stron-gest indicator of costs, 7 there remains a gap in the literature in pairing clinical sequelae of postoperative anastomotic leaks to economic outcomes.

Reported leak rates for colorectal surgery range from 1.5 to $16 \%$ globally; however, definitions of leaks differ between published studies. 8 Furthermore, a review by Kingham and Pachter reported that experienced gastro surgeons often quote 3 to $6 \%$ as a generally acknowledged overall leakage rate. They also compared the definitions across different stud-ies and concluded that there was no uniformly accepted set of criteria. 9 They observed that definitions varied based on com- binations of clinical signs, biochemical markers, radiological findings, and intraoperative findings. Our focus was on clin-ical leaks, as they affect morbidity and mortality. Nonclinical leaks diagnosed by radiology have no clinical effects and resolve without interventions.
\end{abstract}


Our study was undertaken to quantify the incidence of anastomotic leaks in patients under- going colorectal surgery and to assess the clinical and economic burden of anastomotic leaks in terms of extended hospital stay, re-admissions, in-hospital mortality, postoperative infection, and total costs following gastrointestinal anastamosis.

\section{Methods}

Study Design: This study was designed as a retrospective data analysis of hospital-based patients to analyze the health outcomes and medical resource utilization of patients with anastomotic leaks following gastrointestinal surgery $s$ and 0.8-1.9 times higher postoperative infection rates as compared with patients without leaks. Anastomotic leaks incurred additional LOS and hospital costs of 7.3 days and rupees 24,129 respectively,

only within the first hospitalization. Per 1,000 patients undergoing gastrointestinal surgery, the economic burden associated with anastomotic leaks-including hospitalization and re-admission-was established as 9,500 days in prolonged LOS and rupees 28,60,000 in additional costs. Similar results were obtained from both the PSM and GLM for assessing total costs for hospitalization and re-admission.

Conclusions: Anastomotic leaks in gastrointestinal surgery increase the total clinical and economic burden by a factor of 0.6-1.9 for a 30-day re-admission, postoperative infection, LOS, and hospital costs.

\section{Introduction}

\section{Sample Selection}

The database contains a date-stamped log of all billed items by the cost-accounting department, including medications; laboratory, diagnostic, and therapeutic services; and primary and secondary diagnoses for each patient's hospitalization. Identifier-linked enroll-ment files provide demographic and payer information.

Detailed service-level information for each hospital day was recorded; this included details on medication received.

The patient information collected included patient demographics (age, gender, race/ethnicity), clinical characteristics (All Patient Refined Diagnosis Related Groups [APR-DRG] severity, APR-DRG risk of mortality, hospital and admitting characteristics (location and region of hospital, number of beds, teaching status, admission type), primary and secondary diagnoses, primary and secondary procedures, payer, length of stay (LOS), cost of care, drug utilization, department cost and charge details, day- of-stay capture for some variables, and physician specialty.

The APR-DRG, a widely accepted healthcare research methodology, is an indicator of the severity degree of a disease; it is classified into four categories minor, moderate, major, and extreme. Laboratory/culture data were not available for this study.

\section{Inclusion/Exclusion Criteria}

Data on patients $\geq 18$ years of age, who had undergone gastrointestinal anastamosis, were included in the study. All eligible patients underwent gastrointestinal anastamosis, first performed during the study period.

The surgeries considered for inclusion were colectomy, hemicolectomy, or rectum resection.

\section{Outcome Measures}

The primary objectives of this study were to examine the incidence of anastomotic leaks following colorectal surgery and to evaluate the associated clinical and economic burden. Anastomotic leaks were defined by re operation, reanastomosis, stent, colostomy, drainage, and/or abscess within a 30-day window following gastrointestinal anastamosis.

The total costs of hospitalization, including readmission, and by-department costs, were recorded and analyzed. The cost variable we chose represented the actual cost to treat the patient and included all supplies, labor, and depreciation of equipment. In addition, data were analyzed on in-hospital mortality (hospitalization and readmission, individually and combined) and postoperative infection during hospitalization. The definitions used for postoperative infection were based on ICD-9 codes 998.5X and 998.6X, and on nonprophylactic 
antibiotic usage as a proxy for postoperative infections, defined as postoperative exposure to the predefined antimicrobial drugs $\geq 2$ days after surgery and with treatment duration $\geq 7$ days. ${ }^{12}$ Data on discharge status were recorded, including whether patients were discharged to their home, a skilled nursing facility, other institutions, or to a short-term general hospital; unknown reasons and patients' death were also recorded within the discharge data. Data concerning hospital LOS and readmission within 30 days after discharge were recorded individually and combined Covariates used for the analysis included anastomotic leaks (as defined previously); age; race; gender; admission type; type of colorectal index surgery APR-DRG severity level; APR- DRG risk of mortality; and hospital region, location, type, and size.

\section{Results}

\section{Baseline Characteristics}

Records of 101,929 patients who underwent colorectal surgery from 2014 to 2016 were screened. A total of 99,879 records fit the inclusion criteria (Fig. 1). The mean (SD) age of the patients was 63.1 (15.3) years, with $54 \%$ female and $46 \%$ male. Differences were noted in baseline demographic and clinical characteristics, and in age, sex, race, and health plans between patients with and without anastomotic leaks Additionally, significant differences in clinical characteristics were observed between patients with and without leaks, including APR-DRG severity, individual comorbidities, and surgery type. The overall incidence rate for 30-day postoperative anastomotic leaks was $6.18 \%$ (6,174 patients). Annual mean leak rates for 2014, 2015, and 2016 were 5.69, 6.46, and $6.48 \%$, respectively.

\section{Clinical Outcomes}

\section{Mortality and Discharge Status}

Univariate analysis of clinical outcomes showed significant differences in in-hospital mortality for patients undergoing index hospitalization or re- admission; when combined, mortality was reported in $12 \%$ of patients with anastomotic leaks as compared to $4 \%$ of patients without leaks $(\mathrm{P}<0.001)$.

However, after PSM, there were no statistically significant differences in mortality between the two cohorts. The PSM analysis showed significant differences in the discharge status-the proportions of patients with and without anastomotic leaks with a discharge status of "home," "home with nursing care," and "nursing facility "were 31 and $40 \%, 27$ and $23 \%$, and 28 and $24 \%$, respectively.

\section{Postoperative Infection}

Postoperative infection was reported in 27 and 9 $\%$ of patients with and without leaks, respectively. Patients with leaks reported a postoperative infection rate that was 0.8-1.9 times higher than that of patients without leaks.

The subsequent 30-day re-admission was reported in $29 \%$ and $13 \%$ of patients with and without leaks, respectively

When defined by nonprophylactic antibiotic use only, 58 and $33 \%$ of patients with and without leaks, respectively, reported postoperative infection.

\section{Reasons for Re-admission}

Primary diagnoses

Total $(\mathrm{N}=11,079)$

Patients without Patients with anastomotic leak anastomotic $(\mathrm{N}=9,278) \quad$ leak $(\mathrm{N}=1,801)$

Gastrointestinal complications, No. (\%) 2,393

2,001 (22) $392(22)$

Surgical site infection, No. (\%) 1,380 (12) 935 (10)445 (25)

Genitourinary, No. (\%) 767 (7) $671(7) \quad 96(5)$

Cardiac/circulatory, No. (\%) 524 (5) $486(5) \quad 38(2)$

Venous thromboembolism, No. (\%) 819 (7) 733 (8) 86 (5)

Other infections, No. (\%) 769 (7) 661 (7) 108 (6)

Neurologic/nervous system, No. (\%)210 (2) 192 (2) 18 (1)

Aftercare and services for specific procedures, No. (\%) 1,310

(12) 1,194 (13) $116(6)$

Complication of surgical and medical care, not elsewhere classified, No (\%) 1,528 (14) 1,172 (13) 356 (20)

Others, No. (\%) ${ }^{\mathrm{b}} 2,146$ (19) 1,904 (21) 242 (13)

The primary reasons for re-admission of patients with and without anastomotic leaks included surgical site infection (25 vs $10 \%$ ), and gastrointestinal (22\% in both groups) and 
genitourinary (5 vs 7\%) causes. Overall, 14\% of readmissions were related to complications of surgical and medical care.

\begin{tabular}{|l|c|c|cc}
\hline Variable & Overall & $\begin{array}{c}\text { Patient Without } \\
\text { Anastmosis } \\
\text { *Age, mean (SD) }\end{array}$ & $\begin{array}{c}\text { Patient With } \\
\text { Anastmosis }\end{array}$ & P Value \\
*Age & $63.1(15.3)$ & $63.2(15.3)$ & $61.2(15.8)$ & $<0.001$ \\
\hline $18-44$ & & & & \\
$45-54$ & $11,831(12)$ & $10,875(12)$ & $956(15)$ & $<0.001$ \\
$55-64$ & $16,703(17)$ & $15,693(17)$ & $1,010(16)$ & \\
$65+$ & $22,240(22)$ & $20,847(22)$ & $1,393(23)$ & \\
\hline *Sex & $49,105(49)$ & $46,290(49)$ & $2,815(46)$ & \\
\hline Female No. (\%) & $54,080(54)$ & $51,052(54)$ & $3,028(49)$ & $<0.001$ \\
\hline Male & $45,796(46)$ & $42,650(46)$ & $3,146(51)$ & \\
& & & &
\end{tabular}

\section{Economic Outcomes and Hospitalization}

The unmatched univariate analysis showed significant differences in mean LOS between patients with and without leaks (23 vs 9.7 days). For all patients with and After PSM, a number of significant differences were observed in economic outcomes between patients with and without leaks. For patients with leaks, additional average LOS increases of 7.3 days and hospital costs of rupees 24,129 were incurred for hospitalization alone. Patients with leaks had a 1.3fold greater chance of a 30-day re-admission.

After factoring in re-admissions, the average incremental LOS and average incremental hospital cost increased by up to 9.5 days and rupees 28,597 , respectively.

\section{Conclusion}

In conclusion, anastomotic leaks following colorectal surgery increase the total clinical and economic burden by a factor of 0.6-1.9 in terms of additional 30-day re-admission, postoperative infection, LOS, and hospital costs. The results of this study underscore thepotential advantages of cost reduction for patients and hospitals by preventing anastomotic leaks after colorectal surgery. The prevention of postoperative anastomotic leaks must remain a priority for healthcare providers; this will ease a significant clinical and economic burden.

\section{References}

1. Morris AM, Baldwin LM, Matthews B, Dominitz JA, Barlow WE, Dobie SA,
Billingsley KG. Reoperation as a quality indicator in colorectal surgery: a population based analysis. Ann Surg. 2007;245:73-79.

2. Nesbakken A, Nygaard K, Lunde OC. Outcome and late functional results after anastomotic leakage following mesorectal excision for rectal cancer. $\mathrm{Br} \mathrm{J}$ Surg. 2001;88:400-404.

3. Branagan G, Finnis D. Prognosis after anastomotic leakage in colo- rectal surgery. Dis Colon Rectum. 2005;48:1021-1026.

4. McArdle CS, McMillan DC, Hole DJ. Impact of anastomotic leakage on longterm survival of patients undergoing curative resection for colorectal cancer. $\mathrm{Br}$ J Surg. 2005;92:1150-1154.

5. Choi HK, Law WL, Ho JW. Leakage after resection and intraperito- neal anastomosis for colorectal malignancy: analysis of risk factors. Dis Colon Rectum. 2006;49:17191725.

6. Fouda E, El Nakeeb A, Magdy A, Hammad EA, Othman G, Farid M. Early detection of anastomotic leakage after elective low anterior Resection. J Gastrointest Surg. 2011;15:137-144.

7. Vonlanthen R, Slankamenac K, Breitenstein S, Puhan MA, Muller MK, Hahnloser D, Hauri D, Graf R, Clavien PA. The impact of complications on costs of major surgical procedures: a cost analysis of 1200 patients. Ann Surg. 2011;254:907-913.

8. Thornton M, Joshi H, Vimalachandran C, Heath R, Carter P, Gur U, Rooney P. Management and outcome of colorectal anastomotic leaks.Int $\mathrm{J}$ Colorectal Dis. 2011;26:313-320.

9. Kingham TP, Pachter HL. Colonic anastomotic leak: risk factors, diagnosis, and treatment. J Am Coll Surg. 2009;208:269-278.

10. Premier Perspective database 2008. Available at https://www. 
premierinc.com/prs/data/perspective.jsp.

Last accessed February 03, 2013.

11. Yank V, Tuohy CV, Logan AC, Bravata DM, Staudenmayer K, Eisenhut R, Sundaram V, McMahon D, Stave CD, Zehnder JL,Olkin I, McDonald KM, Owens DK, Stafford RS. Comparative effectiveness of in-hospital use of recombinant factor VIIA for off- label indications vs. usual care. Rockville (MD): Agency for Healthcare Research and Quality (US); 2010 May. Available at http://www.ncbi.nlm.nih.gov/books/NBK 98697/. Last accessed May 30, 2013

12. Yokoe DS, Khan Y, Olsen MA, Hooper DC, Greenbaum M, Vostok J, Lankiewicz J, Fraser VJ, Stevenson KB; Centers for Disease Control and Prevention Epicenters Program. Enhanced surgical site infection surveillance following hysterectomy, vascular, and colorectal surgery. Infect Control Hosp Epidemiol. 2012;33:768-773.

13. Parsons L. Reducing bias in a propensity score matched-pair sample using greedy matching techniques. (Paper 214-26). Paper presented at: Proceedings of the 26th annual SAS Users Group International conference, April 22-25, 200. In: SUGI 26 proceedings. (Proceedings of the 26th annual SAS Users Group International conference, April 2225, 2001). 2001; Long Beach, California.

14. Barber J, Thompson S. Multiple regression of cost data: use of generalised linear models. J Health Serv Res Policy. 2004;9:197-204.

15. Karanjia ND, Corder AP, Bearn P, Heald RJ. Leakage from stapled low anastomosis after total mesorectal excision for carcinoma of the rectum. Br J Surg. 1994;81:1224-1226.

16. Rullier E, Laurent C, Garrelon JL, Michel P, Saric J, Parneix M. Risk factors for anastomotic leakage after resection of rectal cancer. Br J Surg. 1998;85:355-358.
17. Lipska MA, Bissett IP, Parry BR, Merrie AE. Anastomotic leakage after lower gastrointestinal anastomosis: men are at a higher risk. ANZ J Surg. 2006;76:579585.

18. Hyman N, Manchester TL, Osler T, Burns B, Cataldo PA. Anastomotic leaks after intestinal anastomosis: it's later than you think. Ann Surg. 2007;245:254-258.

19. Pickleman J, Watson W, Cunningham J, Fisher SG, Gamelli R. The failed gastrointestinal anastomosis: an inevitable catastrophe? J Am Coll Surg. 1999; 188:473482.

20. Gash K, Greenslade G, Dixon A. Enhanced recovery after laparo- scopic colorectal resection with primary anastomosis; accelerated discharge is safe and does not give rise to increased readmission rates. Colorectal Dis. 2012;14:1287-1290.

21. Telem DA, Sur M, Tabrizian P, Chao TE, Nguyen SQ, Chin EH, Divino CM. Diagnosis of gastrointestinal anastomotic dehiscence after hospital discharge: impact on patient management and outcome. Surgery. 2010;147:127-133

22. Bruce J, Krukowski ZH, Al-Khairy G, Russell EM, Park KG. Systematic review of the definition and measurement of anastomotic leak after gastrointestinal surgery. Br J Surg. 2001;88:1157-1168.

23. Hashemi L, Mukherjee L, Morseon M, Sirkar R. Economic impact of anastomotic leaks in colectomy procedures in the USA: 2005-2009. Paper presented at: SAGES 20122012; San Diego, CA.

24. Dor A, Koroukian S, Xu F, Stulberg J, Delaney C, Cooper G. Pricing of surgeries for colon cancer: patient severity and market factors. Cancer. 2012;118:5741-5748.

25. Harrington DT, Roye GD, Ryder BA, Miner TJ, Richardson P, Cioffi WG. A time-cost analysis of teaching a laparoscopic enteroenterostomy. J Surg Educ. 2007;64:342-345. 